\section{$\underset{\substack{\text { hommes } \\ \text { \& migrations }}}{ }$}

\section{Hommes \& migrations}

Revue française de référence sur les dynamiques

migratoires

$1295 \mid 2012$

Algérie - France : une communauté de destin

\title{
Le paradoxe algérien
}

\section{Marie Poinsot}

\section{(2) OpenEdition \\ Journals}

\section{Édition électronique}

URL : http://journals.openedition.org/hommesmigrations/1058

DOI : 10.4000/hommesmigrations.1058

ISSN : 2262-3353

\section{Éditeur}

Musée national de l'histoire de l'immigration

\section{Édition imprimée}

Date de publication : 1 janvier 2012

Pagination : 1

ISSN : 1142-852X

\section{Référence électronique}

Marie Poinsot, « Le paradoxe algérien », Hommes \& migrations [En ligne], 1295 | 2012, mis en ligne le 01 janvier 2014, consulté le 22 septembre 2020. URL : http://journals.openedition.org/

hommesmigrations/1058; DOI : https://doi.org/10.4000/hommesmigrations.1058 


\section{Le paradoxe algérien Par Marie Poinsot, rédactrice en chef}

L'histoire de la revue est née avec l'immigration algérienne. Les Cahiers nord-africains, rebaptisés revue Hommes \& Migrations au milieu des années soixante, présentaient déjà la diversité des situations des travailleurs nord-africains et de leurs familles, pour la plupart algériens et Kabyles. Les objectifs de la publication restent inchangés : la reconnaissance du phénomène migratoire passe d'abord par la co-naissance et la connaissance. La revue fait de l'année 2012 l'occasion de déployer sur deux dossiers l'analyse des relations franco-algériennes à l'aune des migrations qui en constituent l'un des facteurs majeurs.

L'immigration algérienne a connu une histoire paradoxale en France. Au lendemain de l'indépendance algérienne, les immigrés algériens, qui avaient combattu pour l'indépendance de leur pays depuis la métropole, ne rentrent pas. Paradoxe à la fois politique, lié aux aléas des luttes indépendantistes, et économique, puisque la concomitance de la guerre d'Algérie et de la croissance des Trente Glorieuses provoque un appel continu de main-d'œuvre vers la France industrielle auquel répondent les populations algériennes fuyant la misère. Cette croissance de l'immigration s'inscrit dans un contexte de conflits qui vont imprimer l'imaginaire français en réitérant l'héritage colonial fait de racisme et de stéréotypes. Se dessine ainsi une situation post-coloniale exceptionnelle, associée de nos jours, dans l'opinion française, aux situations de ségrégation des grands ensembles qui rassemblent au fil des années les populations immigrées les plus discriminées.

Autre paradoxe, cette immigration algérienne apparaît comme un gage à contretemps de l'œuvre de civilisation que la France souhaitait exercer sur les populations de son empire : la transmission effective d'une langue et d'une culture républicaine que l'on retrouve dans la mobilisation des jeunes générations nées en France pour une reconnaissance officielle de l'histoire et de la mémoire de leurs parents.

Ce dossier analyse également la situation actuelle de l'immigration algérienne en France et des générations suivantes, mais aussi les "enjeux de mémoires", pour reprendre le terme de Benjamin Stora, entre populations qui se revendiquent comme victimes de l'histoire nationale, que ce soient les rapatriés français ou les harkis arrivés en nombre dans une société qui n'étaient pas prête à les accueillir. Les représentations des immigrés algériens et de leurs descendants dans la société française sont étudiées à travers la littérature et le cinéma notamment, ainsi que les émergences culturelles et artistiques liées à la créativité des générations nouvelles.

En 2003, Hommes et Migrations, avec son dossier "Français et Algériens et Algériens français", soulignait la diversification de cette immigration et la double culture des jeunes générations. On peut aujourd'hui tenter d'élargir cette problématique et, en dépit des crises qu'elle traverse, regarder comment, entre les deux sociétés algérienne et française, émerge une "communauté de destin" de plus de trois millions de personnes qui ne sont plus dans une identité double, mais aspirent à construire un espace social et culturel mixte et des identités communes. Je remercie Leila Bousnina d'avoir accepté d'illustrer, comme en 2003, ce numéro à partir des travaux qu'elle mène de Marseille à Lille en passant par Paris et sa périphérie. 